\title{
El ciberacoso como modalidad delictiva
}

\author{
Ariane Huebra Morán
}

Resumen: este trabajo tiene como objeto analizar de forma breve la falta de regulación existente sobre el ciberacoso desde distintos puntos: de una manera general y de una manera más específica (como en el caso del ciberbullying). Con el avance de las nuevas tecnologías estas actuaciones están cada vez más en auge, es por ello que es necesario un refuerzo en esta materia. Sobre todo he de destacar que en este tipo de delitos quienes se ven afectadas mayoritariamente son las mujeres. El gran problema que gira en torno a este tema es la falta de una regulación específica, no contamos con un libro en el Código Penal que se encargue de estos nuevos delitos, y esa falta de regulación supone que no exista una herramienta eficaz que castigue este comportamiento.

Palabras clave: ciberacoso, ciberbullying, internet, modalidad delictiva, regulación, tipos, menores, adultos.

\section{INTRODUCCIÓN Y DEFINICIÓN:}

La globalización, los avances tecnológicos y un sinfín de cosas han cambiado y modificado la forma de percibir la realidad, sobre todo en el caso de las relaciones entre las personas. Gracias a internet, las redes sociales, los móviles o, en otras palabras, cualquier dispositivo tecnológico, han supuesto un avance para el contacto entre las personas. No obstante, todo esto tiene a su vez sus riesgos, pues el acoso a través de las nuevas tecnologías se ha vuelto cada más frecuente y está a la orden del día.

Debo recalcar antes de nada que la palabra ciberacoso - o derivados, como ciberbullying, el cual voy a mencionar en diferentes ocasiones por ser de los más notorios -, no aparece recogida en la RAE. El Diccionario de la lengua española solo hace alusión al acoso o a 
la acción de acosar, por la cual entiende que consiste en "apremiar de forma insistente a alguien con molestias o requerimientos" ${ }^{1}$. Por lo tanto, partimos de la base de que se trata de un término no recogido en nuestro diccionario.

No obstante, diferentes expertos se han atrevido a dar una definición sobre este fenómeno. Por lo general, se entiende que el ciberacoso es aquel mediante el cual se intenta difamar a alguien, acosándole a través de las nuevas tecnologías, bien por un individuo o bien por varios, mediante ataques personales. De entre todas las definiciones que se pueden dar, me gustaría poner de manifiesto la definición dada por la Doctora Parry Aftab, que entiende que se trata de "amenazas, hostigamiento, humillación u otro tipo de molestias realizadas por un adulto contra otro adulto por medio de tecnologías telemáticas de comunicación, es decir: Internet, telefonía móvil, videoconsolas online, etc" ${ }^{2}$.

De esto se desprende que el ciberacoso no incluye a la figura del menor al recalcar que se trata solo de comportamientos realizados entre adultos. Personalmente me posiciono en el otro extremo, y es que entiendo que el ciberacoso es el término genérico, la base de la que se desprenden diferentes tipos de acoso, incluyendo el ciberbullying. Por lo que a pesar de que considero que se trata una definición acertada, omitiría la mención solo a las personas adultas, ya que el menor que acosa a otra persona sigue siendo ciberacoso, si bien más tarde se pueda incluir en alguna modalidad como puede ser el ciberbullying.

Así podemos entender que el ciberacoso es un problema que puede tener diferentes caras y afectar a diferentes sujetos. De manera más ejemplificativa: el ciberacoso sería la circunferencia que aglutina todo y dentro de ella tendríamos diferentes variantes según la situación.

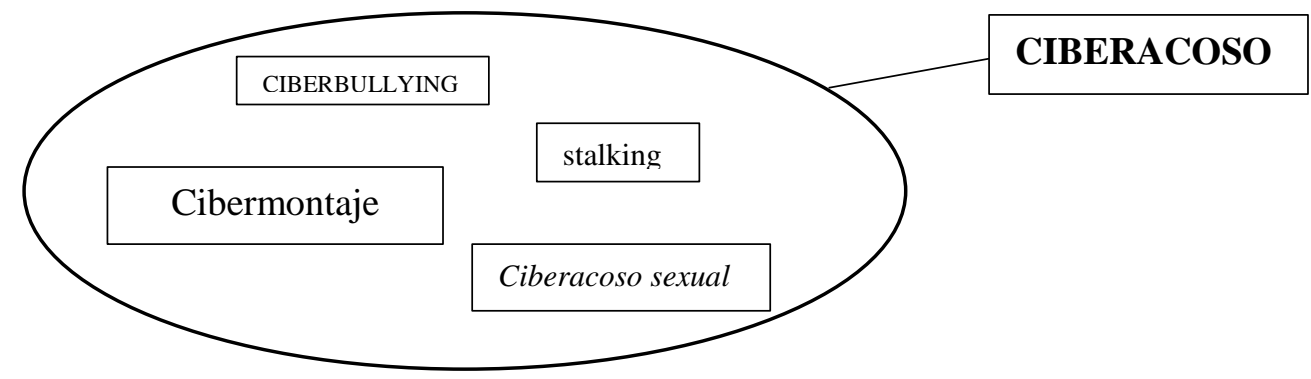

1 Definición extraída del Diccionario de la Lengua Española. Disponible online en http://dle.rae.es/?id=0ZpEHg5 (acceso 20/03/2018).

${ }^{2}$ AFTAB, P. "Guía práctica sobre Ciberbullying”. 2003. Extraído de la web "Ciberacoso". Disponible online en: http://ciberacoso.net/ciberacoso-definicion/ (acceso 20/03/2018). 


\section{TIPOS Y REGULACIÓN:}

Dejando un poco de lado la definición de ciberacoso, me gustaría enfocarme en los tipos y la regulación de este fenómeno, pues más bien es escasa desde mi punto de vista.

En primer lugar, debo mencionar que las formas de acoso a través de los medios electrónicos son amplias (desde colgar fotos en internet hasta crear un perfil falso, todo un sinfín de posibilidades), así como sus tipos, a saber entre otros:

— Insultos electrónicos: intercambio breve y acalorado entre dos o más personas, que tiene lugar a través de algunas de las nuevas tecnologías. Intercambio de emails privados o intercambios en contextos públicos.

- Hostigamiento: mensajes ofensivos reiterados enviados a la persona elegida como blanco por correo electrónico, en foros públicos como salas de chat y foros de debate; envío de cientos o miles de mensajes de texto al teléfono móvil de la persona elegida como blanco. Difiere de los insultos porque el hostigamiento es más a largo plazo, es más unilateral (incluyendo a uno o más ofensores frente a una única víctima).

- Denigración: información despectiva y falsa respecto a otra persona que es colgada en una página web o difundida vía e-mails, mensajes instantáneos, por ejemplo, fotos de alguien alteradas digitalmente sobre todo de forma que refleje actitudes sexuales o que puedan perjudicar a la persona en cuestión.

- Suplantación: el acosador se hace pasar por la víctima, la mayoría de las veces utilizando la clave de acceso de la víctima para acceder a sus cuentas online, y a continuación, enviando mensajes negativos, agresivos o crueles a otras personas como si hubieran sido enviados por la propia víctima.

- Desvelamiento y sonsacamiento: Implica revelar información comprometida de la víctima a otras personas, enviada de forma espontánea pero privada por la personas.

- Exclusión: no dejar participar a la persona de una red social específica.

- Ciberpersecución: envío de comunicaciones electrónicas reiteradas, hostigadoras y amenazantes. 
- Paliza feliz (happy slapping): se realiza una agresión física a una persona a la que se graba en vídeo con el móvil y luego se cuelga en la red para que lo vean miles de personas $^{3}$.

No obstante estas no son las únicas, y es que al final el tipo puede verse modificado continuamente, ya que el modus operandi y las formas de perjudicar a alguien por las redes están en constante evolución. Pero creo que es de mayor interés distinguir a la persona que está perpetrando esa conducta. La razón a esto es sencilla, dependiendo de la edad del sujeto - esto es, si es menor de edad o no - el tratamiento será diferente. Supongamos que nos encontramos en el ámbito escolar, donde se está insultando constantemente a un estudiante por las redes (pasamos del bullying en el mundo real al ciberbullying). En este caso:

- Si el acosador es menor de 14 años no responde penalmente. Será el Ministerio Fiscal el encargado de comunicar a la dirección del centro las cuestiones que considere necesarias respecto al menor. Por su parte, es cierto que el centro deberá llevar a cabo y promover las medidas que considere para poner fin al bullying y proteger al menor acosado.

- En caso de que quien realice el ilícito sea un mayor de edad, acudiremos al Código Penal. Además, será responsable civil por los daños derivados de sus conductas delictivas. Si la conducta puede quedar recogida dentro del artículo $173.1 \mathrm{CP}$, estaríamos ante un "trato degradante" y será castigado con una pena de prisión de 6 meses a 2 años.

- Por el contrario, si esta misma situación la llevara a cabo un menor de edad mayor de 14 años, deberemos acudir al Real Decreto 732/1995, de 5 de mayo de 1995, sobre los derechos y deberes de los alumnos y normas de la convivencia en los centros. Según esta normativa, sería la Administración Educativa y los Órganos de Dirección del centro docente los encargados y responsables de frenar el acoso escolar con las medidas oportunas encaminadas a garantizar la seguridad del acosado: sanciones, expulsiones o reuniones con alumnos/as y padres.

\footnotetext{
3 GARAIGORDOBIL, M. "Prevalencias y consecuencias del Cyberbullying: una revisión”. En Revista International Journal of Psychology and Psychological Therapy, número 2, 2011. Pág. 236.
} 
Ahora bien, aquel mayor de edad que realiza una conducta que se pueda considerar acoso escolar menoscabando gravemente la integridad moral de la víctima, ¿es herramienta efectiva simplemente la pena de prisión? O, por el contrario, ¿dependiendo del caso y de las actuaciones realizadas, se deberían emplear unas herramientas u otras y no solo la de la pena de prisión, atendiendo así a diferentes variables como los derechos afectados? Y es que estos derechos son clave en este problema, ya que son mayores en el mundo de internet al llegar a más personas. Ante esto debería existir una regulación específica y clara, ya que no todas las actuaciones tienen la misma trascendencia y no todo se puede solucionar de la misma forma. ¿O tiene el mismo alcance dejar un insulto en una fotografía de alguien a subir una foto de una persona comprometida y, además, insultándole?

El gran problema es que no existe en el Código Penal ningún apartado que recoja de manera específica el ciberacoso y sus variantes. Desde la reforma de 2015 se puede cubrir en cierta medida esta figura, pero la realidad es que seguimos sin contar con una regulación específica. Sí que es cierto que el stalking o el sexting tienen su apartado específico, con su definición y pena correspondiente:

- El stalking se encuentra recogido en el artículo 172. Ter del Código Penal. En este caso se impondrá la pena de prisión de 3 meses a 2 años o multa de 6 a 24 meses. Además, cuando el ofendido sea algunas de las personas comprendidas en el artículo 173.2, "se impondrá una pena de prisión de 1 a 2 años, o trabajos en beneficio de la comunidad de 60 a 125 días".

- En el caso del sexting lo encontramos regulado en el artículo 197.7 del mismo código, por el cual se impondrá una pena de prisión de 3 meses a 1 año o multa de 6 a 12 meses. Además, "pena se impondrá en su mitad superior cuando los hechos hubieran sido cometidos por el cónyuge o por persona que esté o haya estado unida a él por análoga relación de afectividad, aun sin convivencia, la víctima fuera menor de edad o una persona con discapacidad necesitada de especial protección, o los hechos se hubieran cometido con una finalidad lucrativa".

Ahora bien, ¿qué pasa con el resto de delitos cometidos a través de internet que no cuentan con una regulación diferenciada como en estos dos casos? Para castigar este tipo de conductas deberemos aplicar analógicamente otros delitos que bien podrían encajar con la conducta del ciberacoso analizada en el caso, como por ejemplo: delitos contra la 
intimidad, amenazas, los actos de sabotaje contra soportes electrónicos, delitos contra el honor, coacciones, trato degradante... Tomemos de ejemplo el artículo 143 del Código Penal. Este castiga con la pena de prisión de cuatro a ocho años al que induzca al suicidio de otro. Aquí no se hace mención alguna a las nuevas tecnologías, pero si una persona ha sufrido ciberacoso y acaba suicidándose, es posible la aplicación de este artículo.

Mi pregunta ante esto es: ¿tiene el mismo alcance el acoso sufrido en el mundo real que el sufrido en el mundo de las redes? ¿Merecen el mismo castigo? Como he comentado, es obvio que el alcance es mayor en el mundo virtual por el simple hecho de que esos comentarios pueden verlos mucha más gente y ser partícipes de ese acoso. Siendo de esta manera, deberíamos contar con una ley diferenciada y actualizada para ello, ya que reitero una vez más que los derechos dañados en el ciberacoso son mayores y en mayor porcentaje.

Atendamos así pues a algunas encuestas realizas en torno al ciberacoso para que veamos su auge y alcance de mejor manera:

- Según la encuesta «Global Youth Online Behavior Survey» realizada por Microsoft, el 37\% de los niños de entre 8 y 17 años de 25 países, entre ellos España, señalaron que han sido víctimas de actividades consideradas como ciberacoso ${ }^{4}$.

- Destacar el caso de las mujeres. Estas son víctimas en el 70\% de los casos de ciberbullying, a diferencia del acoso escolar en general donde los afectados están más equilibrados por sexos (47\% mujeres y 53\% varones). Es decir, que "por cada varón que sufre ciberacoso existen 2,4 féminas en su misma situación"5.

\section{CONCLUSIONES:}

De lo expuesto anteriormente se deriva claramente que el sexo que más sufre este acoso es el femenino. Seguramente se deba al espíritu machista que a día de hoy se sigue respirando en nuestra sociedad. Para poder hacer frente a este problema y eliminarlo en su totalidad la herramienta más efectiva es la educación. Hasta entonces considero que el

\footnotetext{
${ }^{4}$ Encuesta obtenida en la web de ABC. Disponible online en: http://www.abc.es/20120627/sociedad/abciciber-acoso-jovenes-201206271825.html (acceso 10/04/2018).

${ }^{5}$ Datos obtenidos en la web de ANAR. Disponible online en: http://www.anar.org/estudio-ciberbullying/ (acceso 10/04/2018).
} 
derecho debe pronunciarse sobre ello, ya que el hecho de que las mujeres sean quienes más sufren esta situación no es algo que se pueda ignorar.

Como he mencionado con anterioridad, dependiendo del caso y de las actuaciones realizadas se deberían emplear unas herramientas u otras y no contar solo la de la pena de prisión o lo que disponga el articulado. Me gustaría recalcar una vez más que los derechos dañados a través del ciberacoso son mayores por el alcance mediático que puede tener el delito. Si atendemos a las leyes actuales, seguramente las medidas que se deben tomar ante situaciones de ciberacoso no son suficientes ni encajan en con el caso por no abarcar todos los supuestos que pueden darse, pero son las únicas soluciones que tenemos en la actualidad. Esto no puede pasar desapercibido, y para ello está claro que debería existir una regulación específica y eficaz.

Por otra parte, tratando el tema de la analogía que he comentado antes, el problema que veo es que lo único que hace es ralentizar el sistema al tener que ir a buscar la solución en diferentes delitos dispuestos por todos el Código Penal en vez de contar con un cuerpo propio para el caso. La consecuencia de esto es que si no existe una herramienta eficaz que castigue este comportamiento muchos casos quedarán en el olvido, y en el peor de los casos a costa de la vida y la salud de muchas víctimas.

De manera que viendo que el uso de la tecnología es mayor día a día, creo que es de vital importancia empezar a tomar mayor control en estos ámbitos. Se hace necesario una constante actualización del Código Penal que permita dar cabida a los recientes ilícitos que están surgiendo en el mundo digital, y castigar este tipo de conductas que generan indefensión en las personas afectadas.

En definitiva, el ciberacoso es una realidad que crece y que puede tener efectos irreversibles. Teniendo en cuenta que es una modalidad tan reciente y nueva, nos urge contar con una ley que nos diga cómo actuar ante esas situaciones, que nos de pautas, que nos diga qué está penado, qué castigos y soluciones nos encontramos para paliar este tipo de comportamiento, y que incluso establezca los derechos que pueden verse afectados. En otras palabras, es necesario una regulación clara y efectiva en este ámbito. 


\section{BIBLIOGRAFÍA:}

GARAIGORDOBIL, M. "Prevalencias y consecuencias del Cyberbullying: una revisión”. En Revista International Journal of Psychology and Psychological Therapy.

Ley Orgánica 10/1995, de 23 de noviembre, del Código Penal.

Real Decreto 732/1995, de 5 de mayo de 1995, sobre los derechos y deberes de los alumnos y normas de la convivencia en los centros.

Recursos online:

- AFTAB, P. “Guía práctica sobre Ciberbullying”. 2003. Extraído de la web "Ciberacoso". Disponible online en: http://ciberacoso.net/ciberacoso-definicion/ (acceso 20/03/2018).

- Diccionario de la Lengua Española (2018). Disponible online en http://dle.rae.es/?id=0ZpEHg5 (acceso 20/03/2018).

- Encuesta Global Youth Online Behavior Survey. Disponible online en: http://www.abc.es/20120627/sociedad/abci-ciber-acoso-jovenes201206271825.html (acceso 10/04/2018).

- Estudio sobre ciberbullying. Disponible en http://www.anar.org/estudio-ciberbullying/ (acceso 10/04/2018). 